\title{
The Path to Living Knowledge Based on the Application of Teaching Information Transformation Techniques
}

\author{
Alexandra Kriulina ${ }^{1, *}$ \\ ${ }^{1}$ Kursk State University, Kursk, Ulitsa Kirova, 5, 305000 Kursk, Russia
}

\begin{abstract}
The author summarizes the author's techniques used in psychology classes with the aim of meaningfully transforming educational information by bachelors into their personal knowledge. The methodology for developing techniques was based on idiographic and qualitative approaches. The productive ideas of V.P. Zinchenko about "living" knowledge and the fundamental difference between information and knowledge, his original and fruitful metaphor about the fifth dimension of being, which he associated with meaning; a consequence of this metaphor about the difficulties of the process of generating an affectively colored space of meanings by a person turned out to be useful. The procedural aspect and content of four specific techniques for transforming educational psychological information are described. Examples of the use of techniques in the study of specific psychological disciplines are given. A special technique of creating and accumulating knowledge about his person by transforming educational psychological information into verbal self-portraits is highlighted. The question is raised about the correspondence of the knowledge obtained by bachelors as a result of the application of the proposed techniques to the content of the concept of "living" knowledge in the understanding of V.P. Zinchenko. The author's version of the answer to this question is offered. A hypothesis is formulated about the possible mechanisms of transformation of educational psychological information into meaningful knowledge of bachelors. Two promising directions for the continuation of the empirical research pre sented in the article are highlighted.
\end{abstract}

\section{Introduction}

The idea of this article was born about five years ago, when carefully rereading the seventh chapter in book by V. P. Zinchenko "Living knowledgeЮ, my attention was drawn to one of the most interesting problems of this chapter: comparison of two concepts "information" and "knowledge" [1]. Of course, the chapter, like the entire book as a whole, contains an abundance of scientific problems. Some problems are formulated explicitly, others need to be guessed. The problem of comparing information and knowledge is presented quite extensively and was encountered for the first time when studying scientific

* Corresponding author: anitim@list.ru 
sources. As shown by further more detailed study of the issue, ideas and considerations expressed by V.P. Zinchenko provide a reliable basis for continuing analytical work in the direction given by these ideas.

Usually the categories "information", "knowledge" and "meaning" are studied by researchers deeply and thoroughly, but without regard to each other. So the monograph of Abdeev R.F. is entirely devoted to the analysis of exclusively the category of "information", the study of the genesis of its content, meaningful characteristics of the information civilization [2]. The relevance of the monograph by Abdeev R.F. increased significantly when interest in digitalization of all spheres of human activity became more widespread in Russian society.

The category "meaning" has been thoroughly and comprehensively studied and described in the well-known monograph by D.A. Leontyev. The author summarizes a lot of studies carried out by domestic and foreign scientists, shows the greatness of human semantic reality, studies the mechanisms of its change and the psychotechnics of influencing it, paid attention to the ways of transmission meanings. One of these ways is training. This point of view is substantiated by the analysis of experimental work carried out under the guidance of E.Yu. Artemyeva. One of such works, according to the author, "gives grounds to speak of learning as a tool for building full-fledged semantic systems ..." $[3$, p. 408]. The result of many years of research work by D.A. Leontyev was the creation of a unified general psychological concept of meaning. At the same time, the author concludes the monograph with a substantiated statement of the fact that the problems of meaning are inexhaustible. The proof is in the appendices to the monograph. They indicate interesting and promising directions for subsequent research into meaning [3].

The category "knowledge" is most often researched in conjunction with such categories as "skills and abilities". The interest of scientists in knowledge has always been high. The quality of this interest changed significantly when the stock of knowledge accumulated by a person began to be considered as the main structural element of human capital, and investments in human capital as the most promising. In this regard, it is noted that "knowledge turns into a key resource, into the main productive force, pushing into the background traditional economic resources - capital, labor, land" [4, p.147]. However, such high assessments of knowledge in the context of human capital research did not lead to the formulation of a significant problem: how is the transformation of information into knowledge carried out in the process of education?

The exception was the monograph by V.P. Zinchenko, in which there was a place for a comparative analysis of two categories in their relationship with the third: "the border between information and knowledge lies along the line of meaning, which is the fifth dimension of being (three coordinates of physical space plus time plus meaning)" [1, p.135 ]. Realizing that the fifth dimension is just a metaphor, the author emphasizes its special value, which is to indicate that "a person generates an affectively colored space of meanings" [1, p.135]. The question of how information makes sense, turning into knowledge, remains open. However, the monograph of V.P. Zinchenko contains a heuristic idea that understanding, drawing out the meaning that is contained in any knowledge, "require special and difficult work" [1, p. 29].

Thus, in the scientific sources available to us, it was not possible to find an answer to the question of how educational information turns into meaningful personal knowledge. This circumstance determined the relevance of the research presented in the article, the purpose of which was to develop special techniques that would allow bachelors to transform educational information into knowledge.

\section{Methods}


The methodological basis of empirical research were two approaches. The idiographic approach provided participants of the study with the opportunity to speak their own language when performing the tasks under study [5]. It was supplemented by a qualitative approach, which, "relying on the critical rationality inherent in science, at the same time allows us to go beyond the immediate logic of experimental research" [6, p. 129]. The productive ideas of V.P. Zinchenko on the fundamental difference between the categories "information" and "knowledge"; his concept of "living" knowledge and the classification of types of understanding were used [1].

To collect empirical facts, the author's projective technique for diagnosing the personality of bachelors [7] was used, which is at the same time a method for analyzing the products of creative activity [8].

To formulate a hypothesis about the mechanisms of the proposed techniques, the method of analogy was used.

To interpret the techniques obtained and tested in the study, the method of comparative analysis was used.

\section{Results}

Both in scientific texts and in real life, most people do not distinguish between the concepts of "information" and "knowledge" and by default use them as synonyms in different contexts. An attempt to explain that these are fundamentally different concepts meets resistance from both teachers and students. In order not to waste time, for some time now, when studying various psychological disciplines, I offer students homework on a comparative analysis of these concepts. It turned out that for most of them the most difficult part of the task is to formulate the signs of difference, which are used for the subsequent comparison of the two concepts. Perhaps this is due to the insufficient level of development of abstract logical thinking, which is confirmed when solving logical problems used at the beginning of seminars as gymnastics for the mind. One more difficulty was discovered when, on an intuitive level, the bachelor feels which feature he would like to highlight, but cannot formulate it verbally or forms it very vaguely, using an excessive number of words.

The experience of using such a task made me think about the quality of assimilation of psychological information. If students do not distinguish between fairly simple concepts, what happens to the assimilation of complex educational texts? Therefore, the technique of comparing concepts has become mandatory in the study of various psychological disciplines. So when studying the discipline "Business Communication" they compare the concepts of "image" and "reputation", "morality" and "ethic", the phenomena of "leadership" and "governance", determine gender differences in the personal image and image of organizations. For greater clarity, the results of the comparative analysis are presented in the form of tables. We consider this technique as training and extremely necessary before turning to other techniques that ensure the transformation of educational psychological information into the personal knowledge of each bachelor.

Only after the accomplished analytical work in comparison of concepts can one seriously discuss more complex issues with bachelors: about the impossibility of direct transfer of knowledge from one person to another, about the high value in monetary terms of personal knowledge as one of the components of human capital, about the advantages of one's own investments in increasing knowledge. To understand the category of "human capital" and to understand the deep connection between knowledge and basic human abilities, we turn to the material of two monographs. In one of them, the domestic concept of human capital was presented for the first time, according to which it is based on four abilities: vitality, which characterizes a person as an individual; working capacity, which is a property of a person as a subject of activity; the ability to innovate, which characterizes a 
person as a person, as a subject of social relations; the ability to learn is a property of a person as an individual, a unique, original self [4].

Three years after the publication of the named monograph, a second monograph on human capital appeared, which is its logical continuation. In it, the concept of human capital gained a rebirth after its experimental testing. As a result, the characterization of each basic ability received a more capacious sound. In this case, comparing the texts of two monographs helps to identify their new content for bachelors. Only through comparative analysis they reveal new, key concepts for understanding the abilities: viability is correlated with the person's way of life, working capacity is related to life position, the ability to innovate is determined by the worldview, and the ability to learn is determined by the picture of the world [9].

The most difficult, but also the most significant for students, is the technique of verbal self-portraits. The well-known idea that there is nothing more interesting for a person than his own person will look banal. The consequences of knowing / not knowing your person are more convincing: according to V.P. Zinchenko, "There is not only a stream of consciousness, but also a stream of life. Awareness of life turns it into true being. Lack of awareness leaves it just existence" [10, p. 35]. The named technique has been developed for almost 20 years. It was based on the method of verbal portraiture, widely known in the humanities. The details of the technique related to the description of the structure of verbal self-portraits and the analysis of their content are detailed in two articles published earlier $[7,11]$. This article describes the features of the application of the technique, which were not reflected in previous publications.

By the end of the third year, bachelors become owners of three verbal self-portraits created in the process of studying three disciplines: "My personality" (general psychology), "I am a professional" (psychology of vocational training), "I am a partner in business communication" (business communication). It is advisable to exchange views of bachelors on the usefulness of these self-portraits so that they can realize the multi-functionality of the new technique. Everyone has his or her own point of view, but the opinion expressed aloud becomes the property of all participants in the discussion. For example, for some of them it is a means of self-reflection, for others it is an opportunity to control their professional plans, for others it is the basis of career planning. The exchange of views allows bachelors to perceive three different self-portraits as one whole. The integrity of the perception of information about one's person, obtained by writing and subsequent repeated adjustments of three self-portraits, enhances the subjective value of each of them.

The final correction of one of the self-portraits - "I am a professional" is carried out in the last eighth semester. At this time, bachelors have two additional sources of new information, by their using they find new touches for a self-portrait. Firstly, immediately before the start of the semester, they undergo industrial practice in one of the colleges in accordance with the direction of training: electromechanical, polytechnic or motor transport. Real educational situations, attending open classes of experienced teachers and masters of industrial training, completing a reporting task to compile a psychological and pedagogical characteristics of one of the college students contain a large layer of useful practical information about the profession of a teacher of vocational training.

Secondly, during the eighth semester, bachelors study the new discipline "Psychology of Professions". Bachelors are given the opportunity to evaluate their chosen profession of a teacher of vocational training through the prism of new theoretical information about the heights of professional development, about professional longevity, about professional culture, about the details of professional self-determination. One can seriously think about how not to fall into the unpromising paths of professional development, described by E.A. Klimov, not to be trapped in work addiction and perfectionism, analyzed in detail by E.P. Ilyin. 
Several circumstances are a reliable motivation for writing self-portraits. As a training, bachelors write a verbal portrait of a stranger or unfamiliar person. At a certain stage in the discussion of these portraits, they develop a sincere interest in the opportunity to paint a portrait of themselves. Studying the psychology of memory in the first year, bachelors got acquainted with the following regularity: information found by a person himself is subjectively valued more and is remembered for a longer period compared to ready information from lectures by a teacher or from a textbook. During the performance of test tasks in practical classes in psychology, bachelors are invited to save the results obtained and find a suitable place for them in the text of self-portraits. These three circumstances make a certain contribution to the motivational basis for writing self-portraits.

The technique of logical processing of information, in our opinion, is necessary in the learning process for the full assimilation of psychological educational information. Firstly, a preliminary survey of bachelors shows that they did not get acquainted with such means at school; secondly, most textbooks on psychology are written in an academic language that is difficult to comprehend and understand, as well as for its subsequent reproduction, as in oral speech when answering at seminars, and in writing when writing term papers and final qualifying works.

As a training, bachelors first learn to single out logical pieces of information in separate sentences, which are obviously difficult to remember, since they consist of a large number of words that exceed the known memory capacity of the average person. The need to isolate semantic portions of a sentence is due to a pattern known to psychologists: it is better to memorize long sentences not literally, but by meaning. Therefore, they are invited to divide the written sentence into semantic portions with the help of vertical bars. After checking the number of allocated semantic portions, the following task is given: using all the richness of the Russian language, reformulate the original sentence so that its meaning is completely preserved. However, only seven words are allowed. The short version of the sentence obtained as a result of paraphrasing is checked for compliance with two rules: the meaning of the original sentence should not be lost and cannot be distorted. Working with sentences is facilitated by the fact that in Russian the meaning is given by verbs. Therefore, the presence of a verb, even in the absence of other members of speech, serves as an indication of the presence of a semantic portion.

The situation with the logical processing of educational texts is more complicated. This type of work with texts made it possible to realize the deep meaning of V.P. Zinchenko that "the text is an invitation, a challenge" [1, p.108]. How should you understand the last two words? An invitation means that the book invites the reader to communicate with its author, in this case by correspondence. Just as in direct communication with partners we not only listen to them, but also listen attentively to the spoken words in order to grasp the meaning of what was said, to understand it in order to achieve mutual understanding, so when reading a book it is necessary to read the text and re-read it. The goal is the same - to understand the author, to extract from the text the meaning that the author has put there. A challenge is most likely the formulation of a task for understanding the text, by solving which the reader will be able to get to the meaning.

In the event that the educational text is structured by the author of the textbook, bachelors can use a ready-made structure to understand its meaning. For example, the chapter of the textbook is divided into paragraphs, and within the paragraphs the semantic portions of the text are in italics. If the text of the textbook is straight, does not contain paragraphs, and there is no italicizing within paragraphs, then the bachelors face the task of independent work on highlighting the semantic portions of the educational text. Not all of them are able to solve the problem on their own. In case of great difficulty, you can go to the group option for solving the problem without the intervention of the teacher or with his help, if difficulties arise during the group approach. 
As an example, we will give one of the options for structuring the text of a textbook by A.V. Karpov "Psychology of Management" [12]. A chapter was selected that describes derived (complex) control functions. First, the substantive characteristics of these functions were highlighted: the features of the tasks solved by the head, the specifics of the implementation of the function in practice, the requirements for the qualities of the head, examples from real practice. Next, a table is built, which must be filled with information from the text of the textbook for each of the four derived functions: integration, strategic, representative, stabilization. For example, in the column "Requirements for the qualities of a leader", when the task is completed correctly, the following entries appear: the presence of systemic thinking (integration function), the ability to delegate responsibility to lowerlevel managers in the management hierarchy (strategic function), the ability to withstand the burden of one's dual position (representative function), mobilization ability (stabilization function).

This technique was practiced with bachelors studying the disciplines "Psychology of Management" and "Psychological Foundations of Personnel Management". We believe that it is acceptable in the process of studying other psychological disciplines. In order for this assumption to take the form of a reasoned statement, it needs empirical verification, which we have outlined as a prospect for continuing the research work begun. The stimulus for the continuation will be a positive assessment of the technique by those bachelors who have already used it. Many of them noticed that the technique contributes to both a better understanding of the text when studying it, and a freer presentation of the studied material at seminars. This fact, found by bachelors, will receive a scientific explanation in the "Discussion" section.

Technique of multidiscipline synthesis of information. Two varieties of the named synthesis were proposed by us back in 1996 [13]. According to this point of view, interdisciplinary synthesis means the synthesis of psychological information from its different areas. Numerous anthologies on various problems of psychology can serve as a convincing example of the effectiveness of interdisciplinary synthesis of scientific information. They synthesize the work of psychologists who have been studying a specific problem in different areas of psychology. Interdisciplinary synthesis means the synthesis of information from different scientific fields. As one of the examples of a successful interdisciplinary synthesis of scientific information, it is appropriate to give a monograph published by the Institute of Psychology of the Russian Academy of Sciences. It contains articles on the problems of life, prepared by scientists representing the following fields of science: psychology, philosophy, sociology, biology [14].

The examples given relate to the synthesis of scientific information. It can be assumed that the named types of synthesis are applicable to educational information. The interdisciplinary synthesis of educational psychological information is realized when bachelors study the discipline "Psychology of vocational training." For example, the completeness and depth of the bachelors' ideas about the world of emotions of the teacher and students can be provided by synthesizing information from general psychology (meaningful characteristics of functions and types of human experiences) with information from labor psychology (oversituational regulation of educational and professional activity with the help of experiences), supplementing it with information from social psychology (experiences as the basis of infection, one of the classic methods of influence). An interdisciplinary synthesis of educational economic and psychological information is appropriate when analyzing the system of means of teacher labor. So the material means of labor are better studied in economics, and functional means in psychology.

The category of "human capital" is interdisciplinary, as it is studied mainly by economists and psychologists, somewhat less often by sociologists. In the descriptions of human capital, psychologists focus on the knowledge and abilities of a person, on the 
cultural factors that determine his development, on the fact that this type of capital is a personal, family and social value.Economists reveal the content of the category "human capital", operating with the following concepts: the cost and investment in human capital, its physical and moral wear and tear, the possibilities of its accumulation and liquidity, personal and private sources of investment in this type of capital. Obviously, in order to achieve mutual understanding between psychologists and economists on the problem of human capital, it is necessary to exchange initial psychological and economic information. The first step in this direction has already been taken. At the present time, the work of the authors developing the problems of the strategic psychology of globalization is the only attempt to present in an orderly manner the theoretical findings of economists and psychologists related to the understanding of human capital [4].

The discipline "Business Communication" is interdisciplinary in content. When studying its main problems, one has to use the information accumulated in psychology (the structure of business communication), cultural studies (features of business correspondence with representatives of different cultures), ethics (the ethical basis of business negotiations), history (principles of doing business in Russia at the beginning of the 20th century). "Organizationalbehavior" canbe attributed to the interdisciplinary ones.

\section{Discussion}

The transition to the interpretation of the techniques obtained is advisable to begin with a discussion of the question of the correspondence of the knowledge of bachelors obtained with their help to the content of the concept of "living" knowledge introduced into the scientific circulation by V.P. Zinchenko. Let us turn to the detailed definition of "living" knowledge: “... living knowledge is not just an inflorescence of different knowledge. In addition to all varieties of knowledge as such, it includes actions (acts, events in its acquisition and use), naturally, memory that performs the function of preserving and accumulating it, attitude to knowledge (consciousness of its presence or absence), and, consequently, the idea of oneself, knowing or not knowing "[1, p. 47].

So let's take a look at the keywords of the definition one after another. The decoding of the expression "inflorescence of different knowledge" is contained in the second chapter of the book by V.P. Zinchenko, which he called "living knowledge: a challenge to science and education." In it, the author offers his understanding of the structure of knowledge: knowledge before knowledge, knowledge as such, knowledge about knowledge, ignorance, ignorance of one's own ignorance, knowledge of ignorance. Of course, it is difficult to expect bachelors to have all the components of the indicated inflorescence. Unambiguously, everyone has knowledge as such or "forms of knowledge that exist in educational systems, in science", as well as some elements of knowledge before knowledge: "attitude, ... unconscious generalizations and conclusions, everyday concepts ...” [1, p.30]. Probably, all other types of knowledge will appear gradually as the development and social maturation of bachelors.

Having learned to work with the text in accordance with the proposed technique, bachelors extract meaning from the information contained in educational texts. According to the classification of types of understanding proposed by V.P. Zinchenko, this means that they are mastering natural understanding. Further, the following task arises: the symbolic design of the extracted meaning for its transmission to communication partners: other bachelors and a teacher. Solving this task will mean mastering a cultural kind of understanding. If this does not happen, then, according to V.P. Zinchenko, we are dealing with mechanical knowledge that does not bear fruit. Actions to master each of the two types of understanding are essentially those events in the acquisition and application of 
knowledge, the mention of which is contained in the detailed definition of "living" knowledge.

The classification of the types of understanding by V. P. Zinchenko contains a third type, called creative. Achieving this level of understanding, along with the ability to denote the meaning extracted from the text and translate it in the process of communication, requires of a person to have another ability - to generate and formalize a new meaning. In our opinion, such a level of understanding could be realized in the research work of bachelors and masters, but alas, practice shows that this happens extremely rarely. The experience of managing the master's program has convinced us that, first, many scientific supervisors do not set the task of creating new meanings for undergraduates. Secondly, undergraduates themselves are not interested in setting and solving such problems. In fact, it all comes down to the fact that the master's thesis, as well as the final qualification work of bachelors, is created and formalized in the best case in six months, in the worst - in two.

In connection with this state of affairs, a new problem, realized in connection with the pandemic and widely discussed in the pages of the psychological newspaper, deserves attention. In accessible language, it is formulated as a refutation of what is ingrained in the minds of many people: thinking does not mature itself. Experimental studies by various scientists have found that approximately 70 percent of adults think on a pre-conceptual level. Apparently, it is no accident that the new standards of higher education include systematic and critical thinking in the list of universal competencies.

What about the memory, which should perform the function of preserving and accumulating knowledge? For this there is a residual knowledge test. At one time, test items came from the Ministry, specially designed to check them. A good result was considered if the students demonstrated 74 percent of the reproduction of residual knowledge. In reality, not all students showed such a result. After a certain time, it is possible to check the residual knowledge of bachelors even without special tests, for example, by polling on a specific discipline they studied a year ago. As such surveys show, the percentage of bachelors who are able to reproduce the knowledge they acquired a year ago is quite low. For example, in a group of nine bachelors, only two bachelors found one hundred percent mastery of the material. Two more were able to reproduce selected fragments from the discipline they studied in the previous year. The rest of the bachelors honestly admitted that they very vaguely remember the issue under discussion, but added with confidence that they had studied it.

Awareness of the presence or absence of knowledge, as well as its lack, appears among bachelors in the process of information exchange. For example, comparing pairs of certain concepts, some bachelors find ten signs for comparison, others less than ten, and some more. Awareness of these individual differences gives each bachelor an idea of the degree of completeness of knowledge obtained with the help of technology, respectively, a subjective idea of oneself as knowing or not knowing enough arises. If the bachelor cannot or is not able to realize this, then he falls into the illusion of understanding. In this case, it is focused not on the discovery of meaning and understanding of educational information, but on memorization and repetition. The situation is aggravated if the bachelor is focused on cramming or the ability to read ready-made information from the screen of gadgets.

While V. P. Zinchenko analyzed meaning in the context of differences between information and knowledge, the authors of the psychological concept of human capital focused on the relationship of meaning with human goals and values. Meaning is understood by them as a product of a person's thinking, bringing him closer to the truth, ordering all the resources of a person to minimize losses and maximize success. The purpose of values is to transform meaning into concrete actions. The purpose of the goal is to translate meaning from a static state to a dynamic one [4]. Such a heuristic move in the 
study of meanings transmits the problem posed and solved in our study into a different context.

The study of meaning-generating techniques in the educational process (the topic of the article) is a special case in relation to the large-scale and in-depth study of meaning techniques implemented in human life, to which the monograph of D. A. Leontiev is devoted to. A significant place in the monograph is occupied by the analysis of the mechanisms of meaning formation: motivational, dispositional and attributive [3]. It is necessary to show the indicated connection between the particular and broader context of the study of the discussed problems, since the most important mental neoplasm of youth, coinciding with the period of study in institutions of higher and secondary vocational education, is the readiness for life self-determination.

The question of the mechanisms of each technique for transforming educational psychological information into personal knowledge remains unresolved. The presence of the concepts "iormation model" and "conceptual model", proposed for use in engineering psychology, gives hope for the possibility of finding mechanisms [15]. Let us make the assumption that educational texts are similar to the information model, and the knowledge that must be obtained by transforming educational texts is similar to the operational conceptual model. This hypothesis, in order to turn it into a scientific truth, needs serious substantiation through a special study that goes beyond the scope of this work.

The need to continue the work begun is directly related to the status of "living" knowledge, which V.P. Zinchenko proclaimed the "true value of education", opposed to the verbalism and conceptualism of the "dogmatic, overorganized and formalized education system" [1, p39]. This is on the one hand. On the other hand, the intensification of the introduction of information-cognitive and digital technologies in the educational process makes it necessary to clarify the concepts of "information security" and "security psychology", as well as the range of problems solved by representatives of a new emerging field of psychology [16]. So far, the attention of researchers of psychological security problems is focused more on the safety and quality of information itself, its protection from external threats and, to a lesser extent, on the protection of the consumers themselves of the growing flow of information, on educating them the ability to competently master and transform information flows.

\section{Findings}

1. Four techniques for transforming educational psychological information are proposed, which have been repeatedly tested in the process of studying psychological disciplines by bachelors who have chosen the profession of a teacher of vocational training. These include: the technique of comparing concepts, the technique of creating verbal selfportraits, the technique of logical information processing, the technique of multidisciplinary information synthesis.

2. The main purpose of using these techniques in the era of informatization of the educational process is outlined: to teach bachelors to turn the original unstructured educational information into personal knowledge filled with personality-colored meaning.

3. It has been proved that the knowledge of bachelors obtained with the help of copyright techniques is "living knowledge" in the understanding of V.P. Zinchenko. They can find all the attributes of "living" knowledge contained in its expanded definition.

4. The emphasis is placed on the broader context of the study of meaning-generating techniques, due to the most important mental neoplasm of youth - the readiness for life self-determination.

5. Prospective directions of continuation of the started research are proposed. One of the directions is testing the hypothesis about the mechanisms of the processes of converting 
information into knowledge. The second direction is the approbation of the technique of logical processing of educational texts, tested with bachelors, future specialists in the field of labor protection and service, in training future teachers.

\section{References}

1. V.P. Zinchenko, Psychological pedagogy. Part I. Living Knowledge ("Samara Printing House", Samara, 1998)

2. R.F. Abdeev, The philosophy of information civilization (VLADOS, Moscow, 1991)

3. D.A. Leontiev, The psychology of meaning (Smysl, Moscow, 2007)

4. A.I. Yuriev, Strategic psychology of globalization: Psychology of human capital (Sciences, prof., Logos, Saint-Petersburg, 2006)

5. R. Corsini, A. Auerbach, Psychological encyclopedia (Peter, Saint-Petersburg, 2006)

6. N. P. Busygina, The problem of the quality of qualitative research: the principle of scientific and ethical validation. Methodology and history of psychology, 4(3), 106 130 (2009)

7. A.A. Kriulina, Idiographic approach to psychodiagnostics of a developing personality. In: V.M. Bekhterev and modern personality psychology: collection of materials of the YI All-Russian scientific conference, 127-129 (Kazan, 2020)

8. N.I. Chuprikova, Methods and methodology of psychological science. Methodology and history of psychology, 2(1), 51-60 (2007)

9. I.S. Burikova, M.A. Konovalova, M.A. Pushkina, A.I. Yuriev, Experience in the psychological measurement of human capital (Moscow, 2009)

10. V.P. Zinchenko, Worlds of consciousness and structure of consciousness. Questions of psychology, 2, 15-36 (1991)

11. A.A. Kriulina, Psychopractic self-knowledge of a teacher in the process of studying psychological disciplines. In: Perspectives and priorities of teacher education in the era of transformations, choices and challenges. In: YI Virtual International Forum on teacher education: collection of scientific papers, 171-179 (Publishing house of Kazan University, Kazan, 2020)

12. A.V. Karpov, Management psychology (Yurayt, Moscow, 2015)

13. A.A. Kriulina, Professional culture and the system of psychological training of a teacher. Macroergonomic approach. Diss. for a job. uch. psycho doctor's degree. (Sciences, Moscow, 1996)

14. A.V. Makhnach, L.G. Wild, Human vitality: individual, professional and social aspects (Publishing house "Institute of Psychology RAS", Moscow, 2016)

15. V.G. Meshcheryakov, V.P. Zinchenko, Big psychological dictionary (AST, Moscow; Prime-EUROZNAK, Saint-Petersburg, 2009)

16. A.I. Dontsov, Yu.P. Zinchenko, O.Yu. Zotova, E.B. Perelygina, Safety psychology (Yurayt, Moscow, 2019) 